\title{
MicroRNA-363-3p/p21(Cip1/Waf1) axis is regulated by HIF-2 $\alpha$ in mediating stemness of melanoma cells
}

\author{
T. HAO, C. X. LI*, X. Y. DING, X. J. XING \\ Department of Dermatology, Chinese PLA General Hospital, Beijing 100853, China \\ *Correspondence: chengxinli0808@sina.com
}

Received August 29, 2018 / Accepted November 8, 2018

\begin{abstract}
Melanoma is a malignant tumor. The acquisition of stemness by melanoma cells aggravates the malignant transformation, which can be regulated by microRNAs (miRNAs, miR). MiR-363-3p is a key tumor-related miRNA, but its role in stemness and melanoma cells is still unknown. Presently, miR-363-3p induced by hypoxia inducible factor (HIF)-2a has a positive role in melanoma cell stemness. The levels of miR-363-3p and HIF- $2 \alpha$ are upregulated in melanoma cell lines. Overexpression of HIF-2 $\alpha$ significantly increased levels of miR-363-3p. However, both HIF-2a knockdown and miR-363-3p inhibition decreased the levels of stemness markers (CD133, CD271, Jarid1B and Nanog). Furthermore, the levels of miR-363-3p and HIF-2 $\alpha$ were upregulated in fluorescence activated cell sorting (FACS)-sorted CD271 ${ }^{\text {high/t }}$ cells. Whereas, miR-363-3p depletion reduced the proportion and the ability of the CD271 high/+ cells to form spheroids, decreased the levels of CD133, CD271, Jarid1B and Nanog with restrained proliferative activity of CD27 $1^{\text {high/+ }}$ cells. Additionally, miR-363-3p was confirmed a key downstream effector of HIF-2 $\alpha$. Intriguingly, cyclin-dependent kinase inhibitor 1A [CDKN1A, p21(Cip1/Waf1)], a key inhibitor of S-phase DNA synthesis and cell cycle progression, was confirmed a target gene of miR-363-3p by luciferase reporter gene assay. The protein levels of CD133, CD271, Jarid1B and Nanog were upregulated with enhanced proliferative activity of CD271 high/+ cells by inhibition of p21 in melanoma cells. In conclusion, miR-363-3p is induced by HIF-2a to promote stemness of melanoma cells via inhibiting $\mathrm{p} 21$. The present study provides novel insights and indicates that HIF-2a/miR-363-3p/p21 signaling may be a potential target in melanoma research and therapy.
\end{abstract}

Key words: melanoma cells, stemness, microRNA-363, hypoxia inducible factor (HIF)-2 $\alpha$, p21(Cip1/Waf1)

Melanoma is one of the most challenging malignant tumors that come from melanocytes. Melanoma is characterized by early blood and lymphatic metastasis and difficult to treat. The five-year survival of melanoma was extremely low $(41.3 \%$ for stage III and $17.8 \%$ for stage IV) [1]. However, there is still a lack of effective early diagnostic markers for treatment of melanoma and is less thorough understanding for the molecular mechanism of melanoma.

A number of researches demonstrated that microRNAs (miRNAs, miR) upregulation in melanoma can drive multiple functions like promoting proliferation, stemness, migration, invasion, and epithelial-to-mesenchymal transition (EMT) of melanoma cells [2]. For example, [3] miR-338-5p expression is upregulated in melanoma tissues and cell lines, and it also promotes the growth and metastasis of malignant melanoma cells [4]. In addition, the upregulation of miR-10b, $21,200 c, 373$ and $520 c$ is found in melanoma cells, which is related with both metastasis and stemness of cancer [5]. MiR-363-3p, a key cancer-related miRNA $[6,7]$, is upregu- lated in adenocarcinoma tissues [8] and is increased in the benign Spitz lesions, a subset of melanocytic skin lesions [9]. Although, miR-363 is increased in melanoma tissues [10, $11]$, the expression pattern and the function of miR-363-3p in melanoma cells is still unknown.

Cancer stem-like cells (CSCs), a small group of heterogeneity cells with stem cells characteristics that exist in tumor tissues, plays key roles in tumor development in a growing number of studies [12]. CSCs are characterized by self-renewal, multi-directional, differentiation, hypertumorigenicity and multidrug resistance. Melanoma stem like cells was first isolated and identified by Fang et al.[13]. After that, CD20, CD133, and CD271 are identified to be the cell surface markers of melanoma cells [13-15]. Melanoma stem like cells could also modulate by miRNAs. It is reported that miR-885-5p could regulate CD133, Nanog and Oct4, the key stem cell factors, and enhances chemoresistance of melanoma cells. Furthermore, miR-363-3p, has been reported to promote human glioblastoma stem cell survival 
and inhibited the expression levels of Bim, another stem cell factor [16]. Additionally, the expression of miR-363-3p target both cancer and stem-cell associate signaling pathways [17]. However, the function of miR-363 on stemness of melanoma cells is unknown.

Hypoxia-inducible factors (HIF) play key roles in the malignant of melanocytes [18] and stemness of cancer cells $[19,20]$, which can upregulated the expression level of miR-363 in K562 cells under hypoxia [21]. Given the involvement of miR-363-3p in melanoma and stemness, we hypothesized that miR-363-3p could be regulated by HIF and involve in the modulation of stemness in melanoma. Therefore, in present study, we attempted to explore the role of miR-363-3p in melanoma and investigate upstream and downstream of miR-363-3p. And we found that miR-363-3p was induced by HIF-2a (EPAS1), a key member of HIF, to promote the stemness of melanoma cells. The expression of p21 (WAF1/Cip1), which was frequently reported to control the cell cycle [22], was confirmed a functional target gene of miR-363-3p, presently.

\section{Materials and methods}

Cell culture. The human melanoma cell lines A2058 and WM793B were obtained from CHI Scientific, Inc. Our laboratory tested the cells every two years by Short Tandem Repeat profiling. A2058 cells were grown in DMEM (Gibco BRL, Grand Island, NY, USA, high glucose) with $10 \%$ FBS, $100 \mathrm{U} / \mathrm{ml}$ penicillin and $100 \mathrm{mg} / \mathrm{ml}$ streptomycin. WM793B were cultured in MCDB153 and L-15 (4:1) with 2\% FBS, $1.68 \mathrm{mM} \mathrm{CaCl}_{2}, 100 \mathrm{U} / \mathrm{ml}$ penicillin and $100 \mathrm{mg} / \mathrm{ml}$ streptomycin. The cells were maintained at $37^{\circ} \mathrm{C}$ and $5 \% \mathrm{CO}_{2}$.

Cell transfection. A2058 and WM793B cells were chosen and seeded respectively in 24-well plates $24 \mathrm{~h}$ before the experiment. Three small interfering RNAs (siRNAs) for HIF-2 $\alpha$ (HIF-2 $\alpha$-siRNA1, HIF-2 $\alpha$-siRNA2, and HIF- $2 \alpha-$ siRNA3) and a negative control siRNA (HIF-2 $\alpha$-si-NC), the siRNAs for $\mathrm{p} 21$ (p21-siRNA1, p21-siRNA2, and p21-siRNA3) and a negative control siRNA (p21-si-NC), and pcDNA3.1p21 (p21) for p21overexpression and its empty vector for negative control (p21-NC) were all constructed through the Shanghai GenePharma company's help (Shanghai, China). The siRNAs for HIF-2 $\alpha$ were used to knockdown the expression of HIF- $2 \alpha$ and the siRNAs for p21 were used to knockdown the expression of p21 in A2058 and WM793B cells, and HIF-2a-pcDNA3.1 (Invitrogen Life Technologies, Carlsbad, CA) was used to overexpression of HIF- $2 \alpha$ and the negative control of HIF-2 $\alpha$-pcDNA3.1 was null-pcDNA3.1 (Invitrogen). Furthermore, these siRNAs, HIF-2 $\alpha$-pcDNA3.1 and null-pcDNA3.1 were respectively transfected cells for 24 h by Lipofectamine ${ }^{\mathrm{Tw}} 2000$ (Invitrogen Life Technologies) according to the manufacturer's instructions.

To knockdown or overexpress miR-363-3p, miR-363-3p inhibitor (miR-363-3p-inhibitor), miR-363-3p-inhibitornegative control (NC), miR-363-3p-mimic (miR-mimic) and
miR-363-3p-mimic-negative control (miR-mimic-NC) were purchased from Genepharma (Shanghai, China). Lentivirus vectors were transduced into cells according to the supplier's instructions. Briefly, cells were cultured in a normal medium for $24 \mathrm{~h}$. Then they were cultured in a medium containing Polybrene (Cruz Biotechnology, Santa Cruz, CA, USA). Thereafter, cells were infected with the lentivirus at the $0.5 \times 10^{5}$ plaque-forming unit ( $\mathrm{pfu}$ ) overnight. The medium was refreshed and incubated overnight without Polybrene. Then, stable clones expressing miR-363-3p were selected with Puromycin dihydrochloride (Santa Cruz Biotechnology).

Additionally, for investigating the effects when $t$ when knocking down HIF-2a combine with overexpressing miR-363-3p or the knocking down miR-363-3p with overexpressing $\mathrm{p} 21$, the HIF- $2 \alpha$ siRNA and miR-mimic were co-transfected into the A2058 cells, as well as pcDNA3.1-p21 and miR-363-3p-inhibitor were co-transfected into cells for $24 \mathrm{~h}$ by Lipofectamine ${ }^{\mathrm{tm}} 2000$ (Invitrogen Life Technologies) according to the manufacturer's instructions.

qRT-PCR. Total RNA in melanoma cells was extracted by using TRIzol reagent (Invitrogen, Carlsbad, CA, USA) according to the manufacturer's instructions. RNA was transcribed into cDNAs using the Primer-Script one step RT-PCR kit (TaKaRa, Dalian, China). To synthesize the miRNA cDNA Synthesis Kit (Takara Biotechnology, Dalian, China) was used. Additionally, a miScript SYBR Green PCR Kit (Takara Biotechnology) was used for analyzing the expression of miR-363-3p. Real time-PCR was performed using the Applied Biosystems 7500 Sequence Detection system (Applied Biosystems, Foster City, CA, USA). The miR-363-3p expression was normalized to U6 (primer: forward, 5'-GCTTCGGCAGCACATATACTAAAAT-3'; reverse, 5'-CGCTTCACGAATTTGCGTGTCAT-3'). $2^{-\Delta \Delta C t}$ method was used for analysis of quantitative changes in gene expression according to the manufacturer's protocols.

Western blot. Briefly, total protein was extracted by super RIPA Lysis Buffer with Benzonase nuclease (HaiGene, Harbin, China). Then, $20 \mu \mathrm{g}$ of total protein was subjected to SDS-PAGE gels. After electrophoresis, the proteins were transferred onto a nitrocellulose filter membrane (PALL, Mexico). After blocking by blocking buffer, the membrane was incubated overnight with the primary antibodies at $4{ }^{\circ} \mathrm{C}$. The following primary antibodies (Abcam, Cambridge, MA, USA) were used: Rabbit anti-HIF-2a (1:500, ab199), CD133 (1:600, ab19898), CD271 (1:300, ab227509), Jarid1B (1:600, ab181089), Nanog (1:800, ab21624), and p21 (1:800, ab109520) and Anti-GAPDH rabbit polyclonal antibody (1:10000, ab181602). The membrane was washed three times with Tween 20/TBS for five minutes each time, and incubated with the appropriate secondary antibody (1:5000. ab222772) for 30 minutes. After washing for three times with Tween20/ TBS, the membrane was treated with the Super ECL reagent (HaiGene, Harbin, China). The blots were detected using an enhanced chemiluminescence western blotting detection (Thermo Fisher Scientific). Densitometric data were 
normalized by GAPDH in triplicate, and the average was shown above the Western blot as the ratio of the control sample.

Cell proliferation assay. The 3-(4,5-dimethylthiazol-2yl)-2,5-diphenyltetrazolium bromide (MTT) assay was used for determining cells viability. Cells in different treatment groups were plated into 96 -well plates at a density of $0.5 \times 10^{5}$ cells per well. We choose 24, 48, 72 and $96 \mathrm{~h}$ after cell transfection, and MTT reagent (Xinshiye Biocompany, Guangzhou, China) were incubated for $4 \mathrm{~h}$ at $37^{\circ} \mathrm{C}$. Subsequently, the supernatant was replaced with dimethyl sulfoxide to dissolve solid residues. A spectrophotometer was used to measure the absorbance at $570 \mathrm{~nm}$.

Cellular immunofluorescence. Cellular immunofluorescence assay was performed to detected the effects of HIF-2a inhibition or miR-363-3p inhibition. The differently transfected A2058 cells in each groups were attached on coverslips, and fixed by $4 \%$ paraformaldehyde, probed with primary antibody at $4{ }^{\circ} \mathrm{C}$ overnight. Then, CD133 was detected using anti-CD133 antibody (1:600, ab19898).

Flow cytometry and fluorescence-activated cell sorting. For further studies, CD271 $1^{\text {high/+ }}$ and CD271 ${ }^{\text {low/- }}$ cells were sorted using a FACSAria flow cytometer (BD Biosciences, San Jose, CA), which was performed as previously published [23].

Sphere-formation assay. After A2058 and WM793B cells were transfected with miR-363-3p-inhibitor for $24 \mathrm{~h}$, the cancer cells were harvested and counted for the tumor spheroid formation assay. The sphere forming cells were respectively established by suspension culture in stem cellcondition medium (containing $1 \mathrm{ml}$ of serum-free DMEM/ F12 supplemented with 2\% B27 (Invitrogen), human recombinant fibroblast growth factor 2 (FGF-2, $20 \mathrm{ng} / \mathrm{ml}$ ) and epidermal growth factor (EGF, $20 \mathrm{ng} / \mathrm{ml}$, Peprotech) and antibiotics penicillin and streptomycin) using ultralow attachment 6-well plates (Corning). After one week of incubation, spheres generated were photographed and sphere number were counted under light microscope The experiment was performed in triplicate [24, 25].

Luciferase reporter assay. The 3'-UTR sequence of p21 predicted to interact with miR-363-3p, or a mutated sequence within the predicted target sites, were inserted into the XbaI/ FseI sites of the pGL3 vector (Promega, Madison, WI, USA). The mutant 3'-UTR of p21 (3'-UTR-mut) was amplified respectively using p21-3'-UTR as the template. DharmFECT Duo transfection reagent (Thermo Fisher Scientific, Glasgow, UK) was used for analysis the luciferase activity analysis. Then, the luciferase assays were performed with the Dual-Glo Luciferase assay system (Promega) according to the manufacturer's instructions.

Statistical analyses. Continuous variables were expressed as the means \pm standard deviation (SD). The quantitative data between groups were compared and analyzed by Student's t-test (two tailed) or a one-way ANOVA followed by Bonferroni post hoc tests, which were analyzed with SPSS version 19.0. A p $<0.05$ was considered to indicate statistically significant differences. Each experiment was repeated at least three times.

\section{Results}

MiR-363-3p is induced by HIF-2 $\alpha$ in melanoma cell lines. Previously, it was reported that miR-363-3p was upregulated in melanoma patients [11]. In order to clarify the expression pattern of miR-363-3p in vitro, we compared the difference of expression of miR-363-3p between human melanocytes (HMs) and the two melanoma cell lines (A2058 and WM793B) by using qRT-PCR. As shown in Figure 1A, in the two melanoma cells, the levels of miR-363-3p was higher than that in the HMs $(\mathrm{p}<0.05)$. We investigated the reason of the upregulation of miR-363-3p. Studies had shown that miR-363-3p could be up-regulated by HIF-1a overexpression [21], we tested the expression levels of miR-363-3p under HIF-1 a overexpression, but there was no changes on miR-363-3p levels (results not shown). We also investigated the expression of HIF-2 $\alpha$, another key member of HIF family [26]. Intriguingly, the expression levels of HIF-2a was also upregulated in A2058 and WM793B ( $<<0.05$, Figure 1B). Importantly, HIF-2 $\alpha$ overexpression by HIF- $2 \alpha-$ pcDNA3.1 induced the overexpression of miR-363-3p in A2058 and
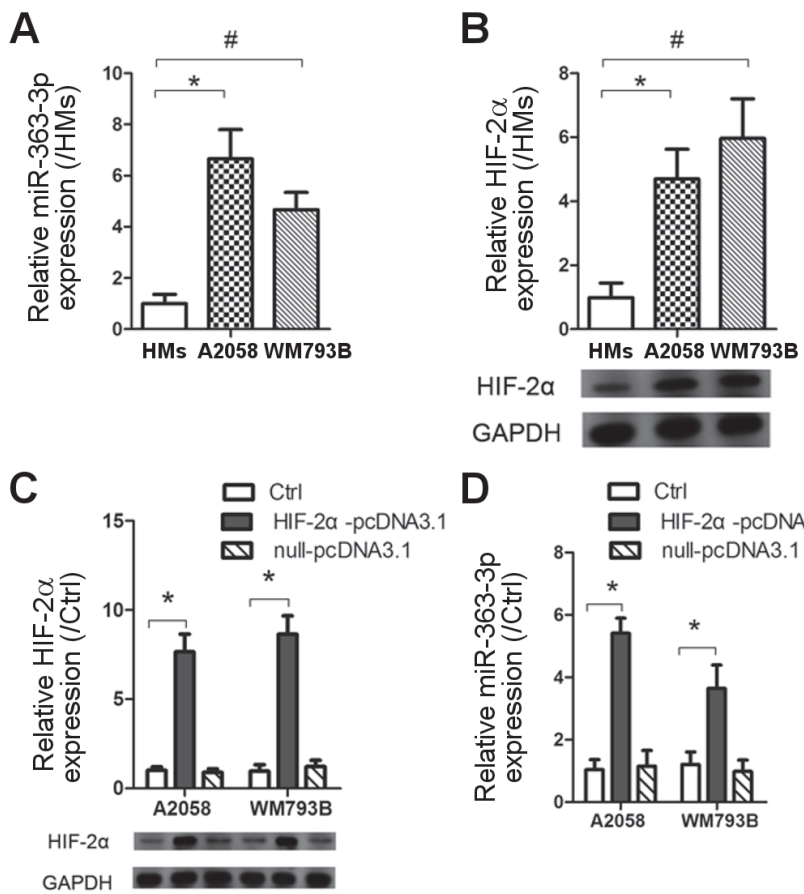

Figure 1. HIF-2 $\alpha$ induces miR-363-3p in melanoma cells. A) The expression levels of miR-363-3p in HMs and two melanoma cells (A2058 and WM793B) were measured by qRT-PCR. B) The expression of HIF-2 $\alpha$ in A2058 and WM793B were measured by Western blot. C) The expression of HIF- $2 \alpha$ was controlled by HIF-2 $\alpha$-pcDNA3.1 in A2058 and WM793B cells. D) The levels of miR-363-3p were regulated by HIF-2 $\alpha$-pcDNA3.1 in A2058 and WM793B cells. ${ }^{*} \mathbf{p}<0.05,{ }^{*} p<0.05$. All experiments were repeated three times. All experiments were repeated three times. 


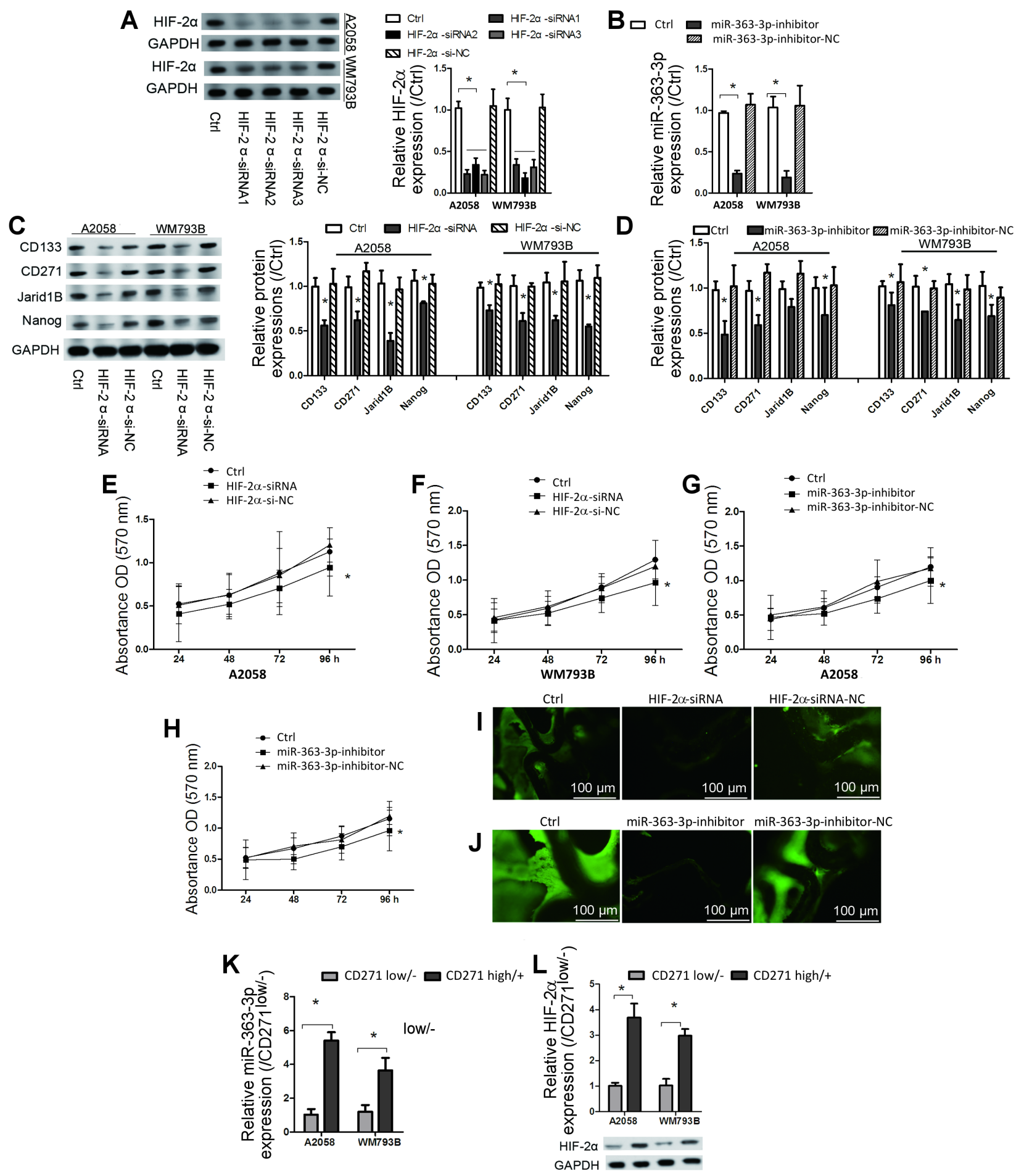

Figure 2. The effects of both miR-363-3p and HIF-2 $\alpha$ on the stemness of melanoma cells. A) The expression of HIF-2 $\alpha$ was controlled by HIF-2 $\alpha$-siRNA in A2058 and WM793B cells. B) The expression of miR-363-3p was controlled by miR-363-3p-inhibitor in A2058 and WM793B cells. " $P<0.05,{ }^{*} P<$ 0.05. C) The expression levels of stemness markers (CD133, CD271, Jarid1B, and Nanog) were measured by Western blot in HIF-2 $\alpha$-siRNA transfected A2058 and WM793B cells. ${ }^{\star}$ p $<0.05$ vs. Ctrl. D) The expression levels of stemness markers (CD133, CD271, Jarid1B, and Nanog) were measured by Western blot in miR-363-3p-inhibitor transfected A2058 and WM793B cells. ${ }^{*} p<0.05$ vs. Ctrl. E and F) The proliferation of HIF-2a-siRNA transfected A2058 and WM793B cells were detected at the time points $24,48,72$ and $96 \mathrm{hr}$ by MTT assays. ${ }^{*} \mathrm{p}<0.05$ vs. Ctrl. $\mathrm{G}$ and $\mathrm{H}$ ) The proliferation of miR-363$3 \mathrm{p}$-inhibitor transfected A2058 and WM793B cells were detected at the time points 24, 48, 72 and $96 \mathrm{hr}$ by MTT assays. ${ }^{*}$ p $<0.05$ vs. Ctrl. I and J) The CD133-positive A2058 cells were tested by cellular immunofluorescence. K) The level changes of miR-363-3p in CD271 ${ }^{\text {low } /-}$ and CD271 ${ }^{\text {high//+ }}$ menlanoma cells. L) The level changes of HIF- $2 \alpha$ in CD271 ${ }^{\text {low/ }}$ and CD271 ${ }^{\text {high// }}$ melanoma cells. ${ }^{*} \mathrm{p}<0.05$. All experiments were repeated three times. 
WM793B cells, presently ( $p<0.05$, Figures $1 C, 1 D)$. Thus, these results above demonstrated that miR-363-3p levels were induced by HIF-2 $\alpha$ in melanoma cell lines suggesting that miR-363-3p might be a key regulator in melanoma cells.

Knockdown of HIF-2 $\alpha$ or inhibition of miR-363-3p suppresses the stemness markers in melanoma cells. We speculated that the miR-363-3p and HIF-2a might be involved in regulating the stemness of melanoma cells. In the present study, both HIF-2 $\alpha$ knockdown by HIF- $2 \alpha$-siRNA and miR-363-3p-inhibitor in the melanoma cells inhibited the expression levels of CD133, CD271, Jarid1B, and Nanog $(\mathrm{p}<0.05$, Figures $2 \mathrm{~A}-\mathrm{D})$, as well as decreased the proliferative activity of melanoma cells $(\mathrm{p}<0.05$, Figures $2 \mathrm{E}-\mathrm{H})$. In addition, the positive expression of CD133 was also detected by cell immunofluorescence method. It was shown that both HIF-2a-siRNA and miR-363-3p-inhibitor inhibited the positive expression of CD133 (Figures 2I, 2J). Furthermore, we sorted the CD271 $1^{\text {high/+ }}$ cells by FACS from A2058 and WM793B. Compared with CD271 $1^{\text {low/- }}$ subpopulation, the levels of miR-363-3p and HIF-2a were significantly upregulated in CD271 $1^{\text {high } /+}$ cells $(\mathrm{p}<0.05$, Figures $2 \mathrm{~K}, 2 \mathrm{~L})$. It was suggested that both HIF-2 $\alpha$ and miR-363-3p played a positive role in the stemness of melanoma cells.

Inhibition of miR-363-3p inhibits the stemness of $\mathrm{CD}_{271^{\mathrm{high} /+}}$ cells. We directly verified the effect of miR-363-3p on CD271 1 high/+ cell stemness. MiR-363-3p downregulation decreased the number of $\mathrm{CD} 271^{\mathrm{high} /+}$ cell proportion $(\mathrm{p}<0.05$, Figure $3 \mathrm{~A})$ and inhibited the proliferation activity of CD271 $1^{\text {high/+ }}$ cells $(p<0.05$, Figures $3 B, 3 C)$, as well as downregulated the protein levels of CD133, Jarid1B and Nanog $(\mathrm{p}<0.05$, Figure 3D). In miR-363-3p downregulation conditions, the spheroidization of the CD271 high/+ cells in non-adherent serum-free media was significantly downregulated ( $\mathrm{p}<0.01$, Figure $3 \mathrm{E}$ ). Additionally, the A2508 cells and CD271 $1^{\text {high/+ }} 2508$ cells were respectively co-transfected with miR-mimic and si-HIF- $2 \alpha$, the expression of the stemness markers (CD133, Jarid1B and Nanog) were partly upregulated in both A2508 cells and CD271 ${ }^{\text {high/+ }} 2508$ cells in comparison to si-HIF- $2 \alpha$ alone ( $p<0.05$, Figures $3 F, 3 G)$. It is indicated that miR-363-3p plays a negative role in cell stemness and partially relieves the inhibition role of HIF-2 $\alpha$ knockdown on the stemness markers.

MiR-363-3p is a key downstream of HIF-2 $\alpha$. Because miR-363-3p levels were induced by HIF-2 $\alpha$ in melanoma cell lines, we further confirmed the relationship between HIF-2 $\alpha$ and miR-363-3p. Our results showed that there was no effect of miR-363-3p knockdown on the expression of HIF-2a in either $\mathrm{CD} 271^{\mathrm{high} /+}$ or CD271 $1^{\text {low/- }}$ proportion $(\mathrm{p}>0.05$, Figures 4A, 4B). Thus, miR-363-3p was a key downstream of HIF-2 $\alpha$ in melanoma stem-like cells.

p21 $1^{\text {Cip1/Waf1 }}$ is a functional target gene of miR-363-3p. Additionally, the putative target genes of miR-363-3p were predicted by bioinformatics software and website. Intriguingly, p21, a key inhibitor of S-phase DNA synthesis and cell cycle progression $[27,28]$, was confirmed a target gene of $\mathrm{miR}-363-3 \mathrm{p}$ by luciferase reporter gene assay $(\mathrm{p}<0.05$, Figures 5A, 5B). MiR-363-3p inhibition upregulated the expression levels of p21 in these two melanoma cells $(\mathrm{p}<0.05$, Figure 5C). p21 was inhibited by siRNA (p21-siRNA) in the melanoma cells $(p<0.05$, Figure $5 \mathrm{D})$, however, we found that the proportion of CD271 high/+ cells and the protein levels of CD133, CD271, Jarid1B and Nanog were all upregulated $(\mathrm{p}<0.05$, Figures 5E, 5F). Additionally, the A2058 cells were co-transfected with miR-363-3p-inhibitor and p21-overexpressed recombinant plasmid, the expression of the stemness markers (CD133, Jarid1B and Nanog) were decreased in A2508 cells in comparison to miR-363-3p-inhibitor alone $(p<0.05$, Figure $5 G)$. Furthermore, the proliferation of the melanoma cells in $\mathrm{p} 21$-siRNA groups were increased $(\mathrm{p}<0.05$, Figures $5 \mathrm{H}, 5 \mathrm{I})$. It is indicated that $\mathrm{p} 21$ is a functional target gene of miR-363-3p. In conclusion, miR-363-3p was induced by HIF- $2 \alpha$ to promote the stemness of melanoma cells via inhibiting $\mathrm{p} 21$. The present study provides novel insights that HIF-2a/miR-363-3p/p21 signaling may be a potential target of research and therapy of melanoma.

\section{Discussion}

The abnormal expression of miR-363-3p, which has a key role in proliferation, migration, and invasion of cells [29], was frequently reported in various types of malignant tumors [11] and normal endothelial cells, $[30,31]$. Philippidou D et al. [11] showed that miR-363-3p was upregulated in human melanoma tissues, but was not upregulated in breast cancer, whereas Beltran AS et al. [32] suggested that miR-363-3p was a potential oncogenic miRNA in breast cancer. Conti A et al. [30] also found that miR-363-3p was upregulated in human glioma. Consistent with these results, our study shows that miR-363-3p is expressed with higher levels in melanoma cell lines than in HM cells, suggesting that miR-363-3p may play a role of oncogenic gene in melanoma.

Furthermore, we detected that the stemness markers and proliferation of the melanoma were inhibited by miR-363-3p inhibition. Conti A et al. [30] demonstrated that miR-363-3p promoted glioma cell viability and its inhibition induced downregulation of AKT, cyclin-D1, matrix metalloproteinase (MMP)-2, MMP-9, and Bcl-2 and upregulation of caspase 3 in glioma [30]. More importantly, in glioblastoma multiform tissues, miR-363-3p was upregulated and promoted human glioblastoma stem cell survival via inhibiting caspase-3, caspase-9, and Bim [16]. It has been indicated that miR-363-3p has a key role in cancer cell stemness. Previous studies confirmed that transplantation of human $\mathrm{CD} 271^{+}$melanoma cells into engrafted human skin or bone in Rag2(-/-)gammac(-/-) mice resulted in melanoma, and $\mathrm{CD} 271^{+}$melanoma cells were proven to be "genuine cancer stem cells" [15]. Thus, the CD271 $1^{\text {high/+ }}$ melanoma cells were sorted and the levels of miR-363-3p was also upregulated in CD271 $1^{\text {high/+ }}$ cells compared to CD271 $1^{\text {low/- }}$ cells. Furthermore, miR-363-3p inhibition decreased the ability of melanoma 

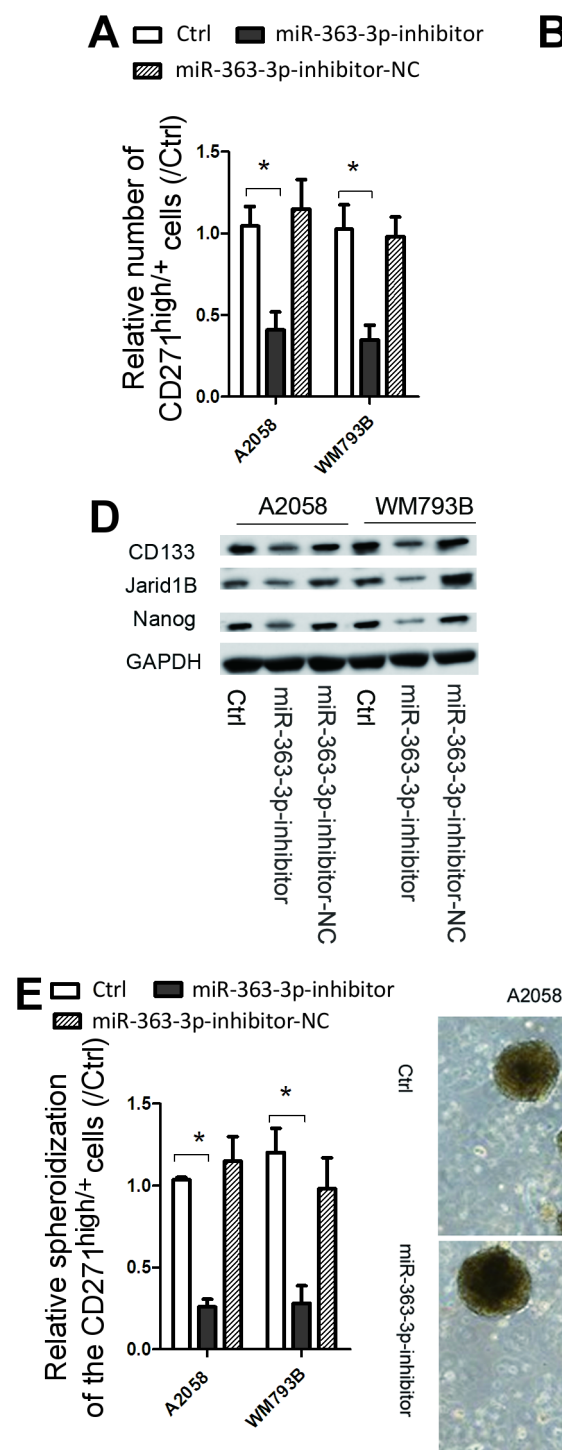

B

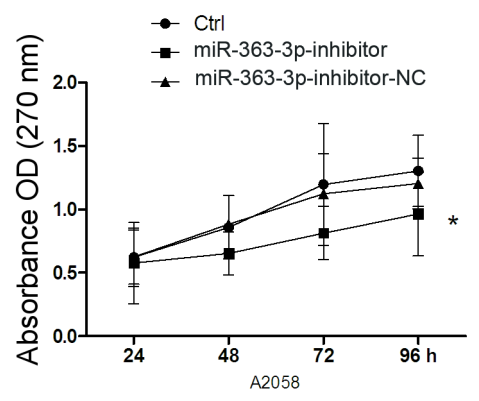

C

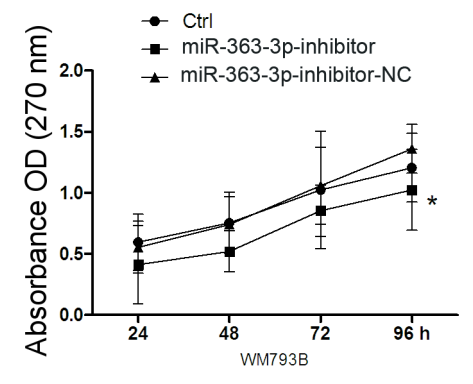

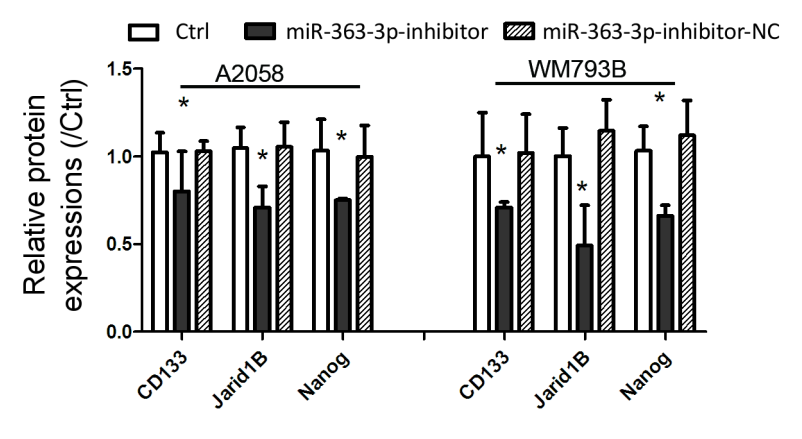
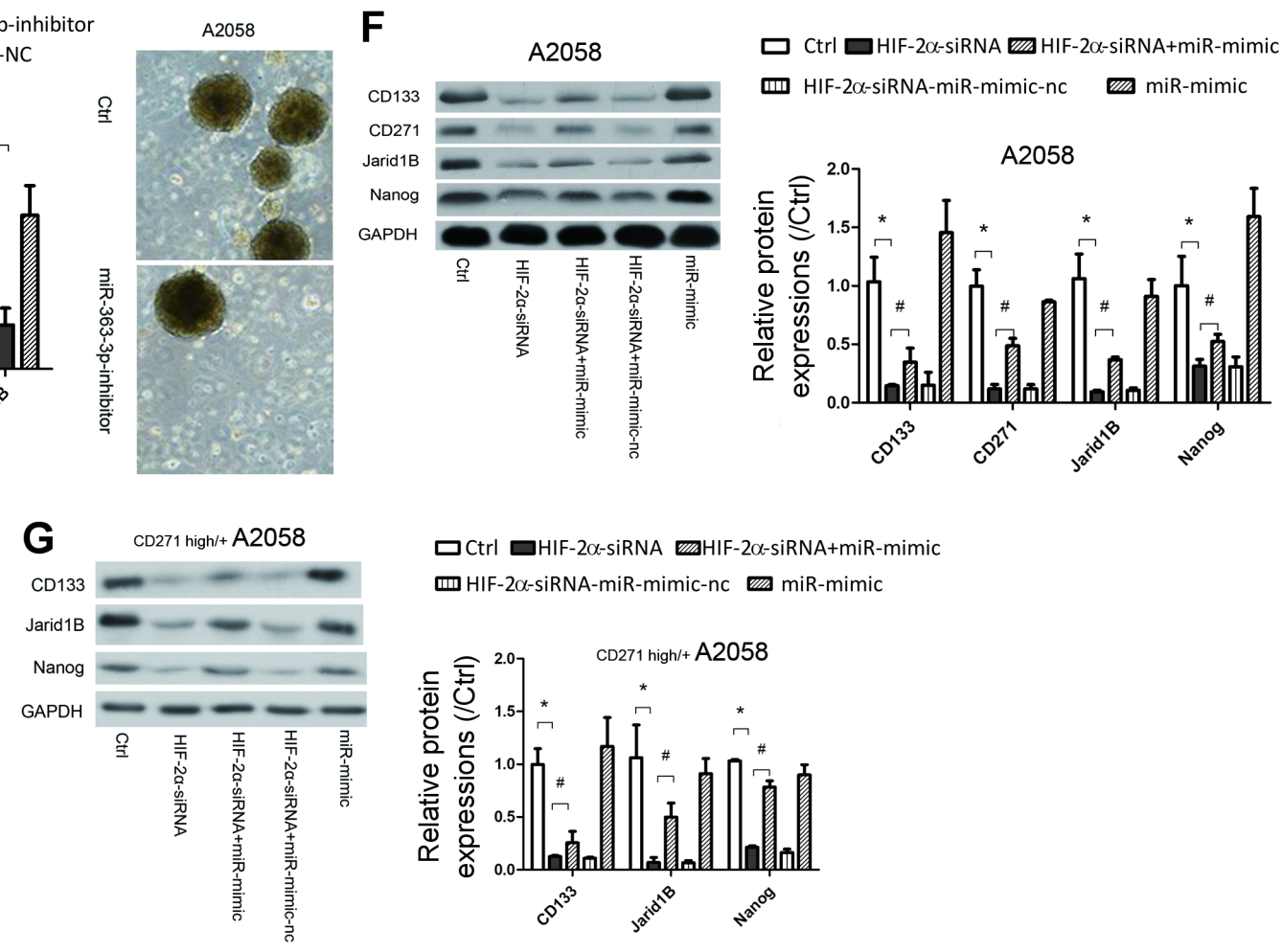

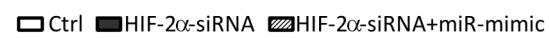

四HIF-2 $\alpha$-siRNA-miR-mimic-nc miR-mimic

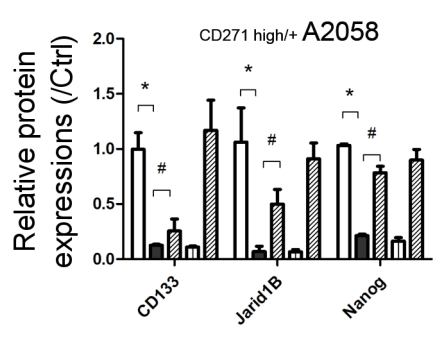

Figure 3. The effects of miR-363-3p on the stemness of CD271 ${ }^{\text {high/+ }}$ melanoma cells. A) The relative number changes of CD271 high/+ cells in miR-3633 p-inhibitor transfected CD271 ${ }^{\text {high/+ }}$ melanoma cells. $\mathbf{p}<0.05$. B and C) The proliferation of miR-363-3p-inhibitor transfected CD271 ${ }^{\text {high/+ }}$ cells were detected at the time points $24,48,72$ and $96 \mathrm{~h}$ by MTT assays. ${ }^{\star} \mathrm{p}<0.05$ vs. Ctrl. D) The expression levels of stemness markers (CD133, CD271, Jarid1B, and Nanog) were measured by Western blot in miR-363-3p-inhibitor transfected CD271 ${ }^{\text {high } /+}$ cells. ${ }^{*} \mathrm{p}<0.05$ vs. Ctrl. E) Relative spheroidization in the miR-363-3p-inhibitor transfected CD271 ${ }^{\text {high/+ }}$ cells. F and G) The expression levels of stemness markers (CD133, CD271, Jarid1B, and Nanog) were measured by Western blot in miR-363-3p-mimic (miR-mimic) and HIF-2 $\alpha$-siRNA co-transfected A2058 and CD271 ${ }^{\text {high } /+}$ A2058 cells. ${ }^{*}$ p $<0.05,{ }^{\star}$ p $<0.05$. All experiments were repeated three times. 

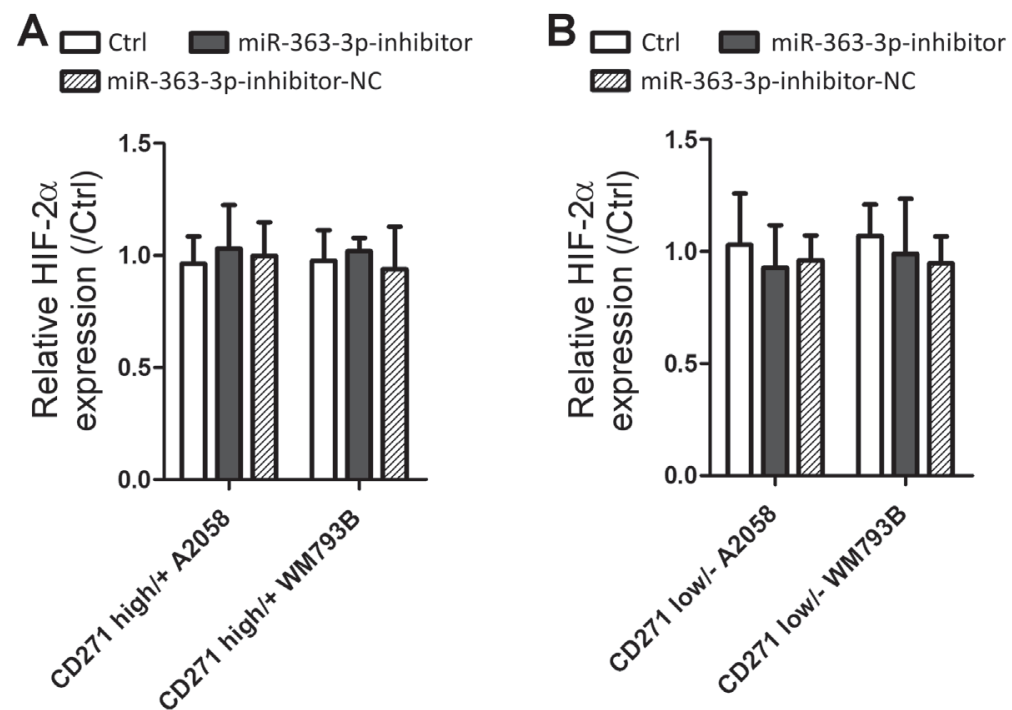

Figure 4. miR-363-3p did not change the expression of HIF-2 $\alpha$ in CD27 $1^{\text {high/+ }}$ or CD27 $1^{\text {low/- }}$ cells. A and B) The expression levels of HIF-2 $\alpha$ in CD27 $1^{\text {high/+ }}$ or CD271 ${ }^{\text {low/- }}$ cells were tested by Western blot. All experiments were repeated three times.

cells to form spheroids, the proportion of CD27 ${ }^{\text {high/+ }}$ cells, inhibited the proliferative activity of $\mathrm{CD} 271^{\text {high } /+}$ cells and downregulated stemness markers. Our results confirm that miR-363-3p inhibition reduces melanoma stem-like cell phenotype and proliferation.

The upstream regulator of miR-363 was further investigated in the present study. Studies demonstrated that HIF-1a induced the levels of miR-363 in K562 cells, a chronic myeloid leukemia cell line [21], whereas there was no obvious effect on miR-363 in A2058 and WM793B. HIF-2a, another member of HIF family and an important inducer of stemness marker Oct-4 [33], was presently confirmed a positive regulator of miR-363-3p. In the present study, HIF- $2 \alpha$ was upregulated in the melanoma cells, and HIF- $2 \alpha$ knockdown also inhibited the expression levels of CD133, Jarid1B, and Nanog in melanoma cells. Additionally, HIF-2a overexpression remarkably upregulated miR-363-3p, but miR-363-3p overexpression or inhibition had no effects on HIF-2a expression levels in the melanoma cells, suggesting that HIF-2 $\alpha$ is an upstream positive regulator of miR-363-3p. A number of studies support our research. Ohnishi $S$ et al. [34] revealed that HIF-2 $\alpha$ could activate CD133 promoter in human colon cancer cell line. Petruzzelli $\mathrm{R}$ et al.[35] demonstrated that HIF- $2 \alpha$ enhanced Nanog expression and enhanced stemness by binding to an oct-sox cis-regulatory element in the NANOG promoter in human embryonic stem cells. Our further results found that the level of HIF- $2 \alpha$ is enhanced in the CD271 $1^{\text {high/+ }}$ cells. These studies suggest that HIF-2 $\alpha$ might be another inducer of stemness in melanoma by inducing the upregulation of miR-363-3p.

We further confirmed that p21 was a functional target gene of miR-363-3p. p21 was demonstrated to be negatively-related to melanoma cell proliferation [27], cell cycle [36] and apoptosis [37]. By inhibition of p21 in melanoma cell lines, the proliferative activity of CD271 high/+ cells was upregulated. Similarly, FOXD3 is an inhibitor of cell proliferation and G1-S progression in melanoma, and knockdown of p21 partially restored the G1-S progression in FOXD3-expressing melanoma cells [36]. Therefore, it has been indicated that inhibition of p21 induced proliferation of melanoma cells. More importantly, the protein levels of CD133, Jarid1B and Nanog in melanoma cells were upregulated upon p21 inhibition. In mesenchymal stem cells, p21 knockdown by siRNAs also increased cell proliferation, percentage of cells in S phase and the expression levels of Oct-4 and Nanog [38]. Furthermore, p21 can be a target gene of a number of miRNAs [39], such as miR-299-5p in acute promyelocytic leukemia cells [40] and miR-423-3p in colorectal cancer cells [41]. We confirmed that the miR-363-3p bound directly to the 3' UTR region of p21, inhibited the protein levels of p 21 in melanoma, suggesting that miR-363-3p/p21 axis is a key pathway in regulating stemness of melanoma cells.

Of course, some issues of our work should be addressed. In the present study, HIF-2 $\alpha$ overexpression upregulated miR-363-3p levels in the melanoma cells. Similarly, miR-363-3p could be up-regulated by HIF- $1 \alpha$ overexpression [21]. However, there was no significant effect of miR-363-3p on the expression levels of HIF- $2 \alpha$, indicating that there was no miRNA-target relationship between miR-363-3p and HIF-2 $\alpha$. Thus, a limitation of the present study is that the mechanism by which HIF-2a regulates miR-363-3p in melanoma cells remains unknown. However, miR-363-3p could be inhibited by long non-coding RNA (lncRNA) 
A

$$
\begin{array}{rcr}
\text { miR-363-3p } & 5 \text { AAUUGCACGGUAUCCAUCUGUA } \\
\text { I I I I I I I } \\
\text { WT-p21-3'UTR } & 3 ' \ldots \text { CGGGGAAGUUUCAGGUAGACAA... }
\end{array}
$$

Mut-p21-3'UTR $\quad 3$ '... CGgGGAAGUUUCAGGAACUGUA...

C

Ctrl $\square$ miR-363-3p-inhibitor
miR-363-3p-inhibitor-NC

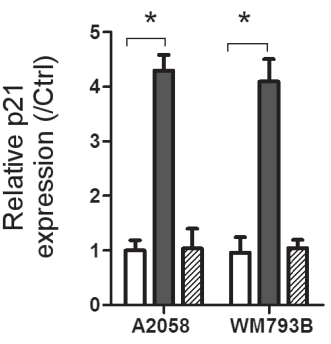

p21- $--=$

GAPDH
D
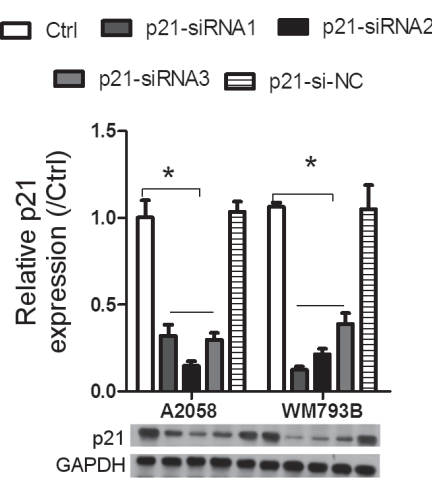

B

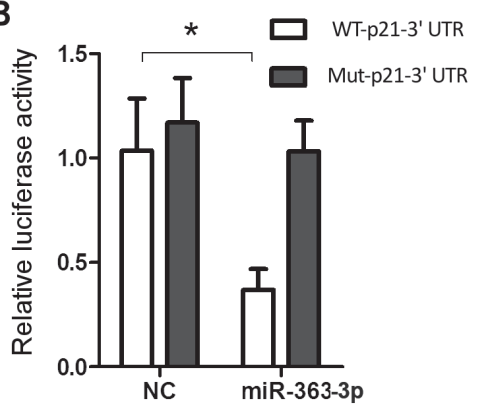

E

$\mathbf{F}$
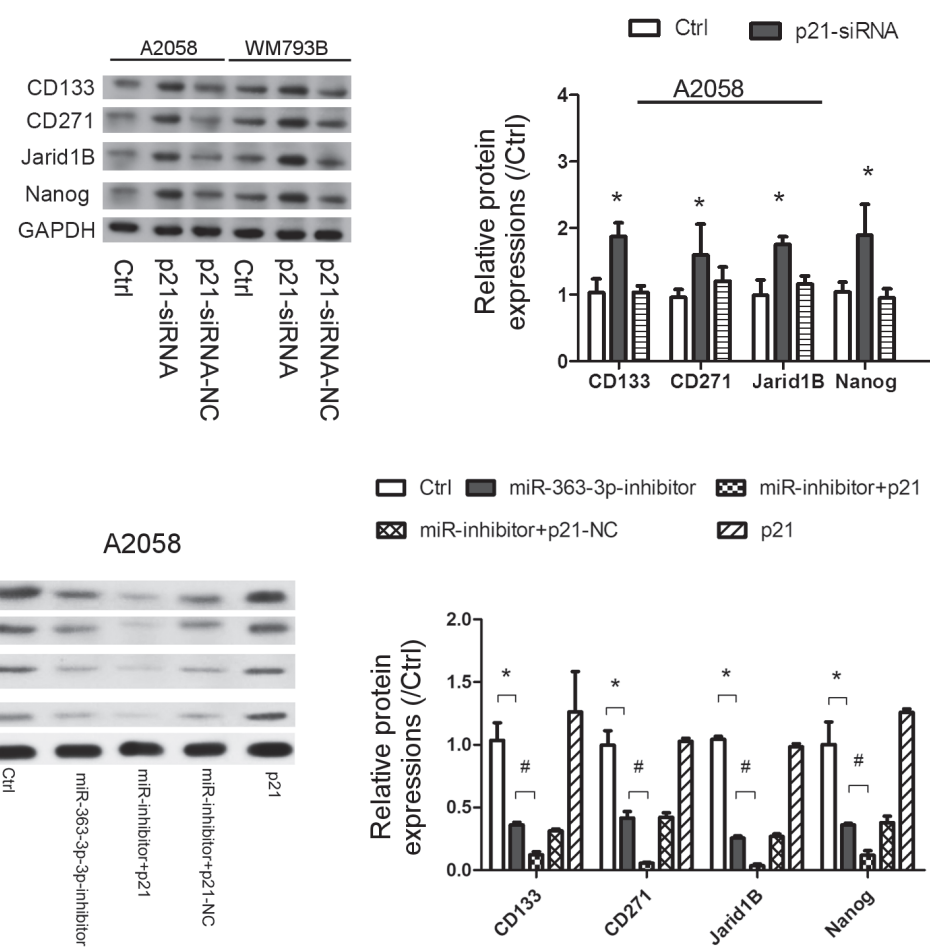

曰 21 -si-NC

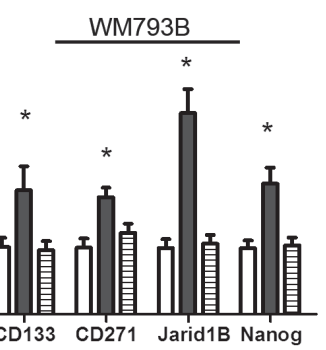

$\mathrm{H}$

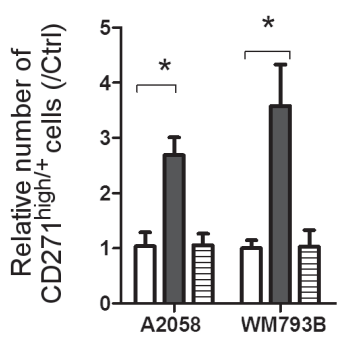

G

A2058

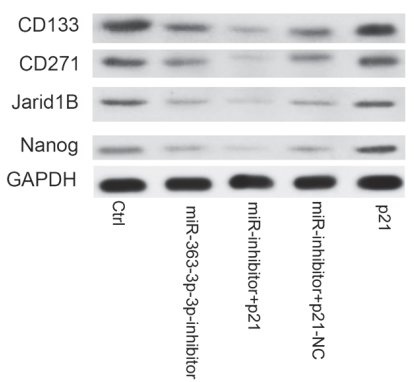

$\square$ Ctrl $\square$ miR-363-3p-inhibitor $\mathbb{x}$ miR-inhibitor+p21

四iR-inhibitor+p21-NC

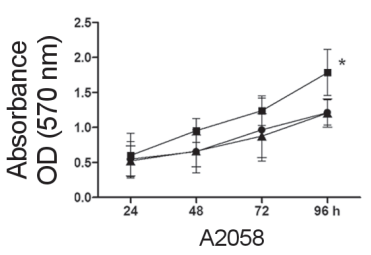

I

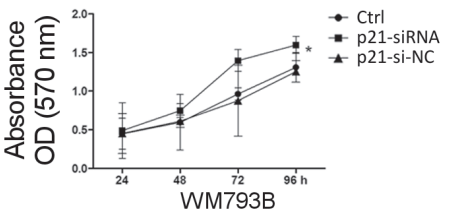

Figure 5. p21 is a key target gene of miR-363-3p. A and B) Interaction of between miR-363-3p and p21 was tested by dual-luciferase reporter assay. ${ }^{\star} \mathrm{p}<0.05$ vs. NC. C) $\mathrm{p} 21$ protein level changes were tested by Western blot in the miR-363-3p-inhibitor transfected melanoma cells. p $<0.05$. D) p21 protein level changes were tested by Western blot in the p21-siRNA transfected melanoma cells. $p<0.05$. E) The relative number changes of CD271 ${ }^{\text {high } /+}$ cells in the p21-siRNA transfected melanoma cells. $\mathbf{p}<0.05$. F) The expression levels of stemness markers (CD133, CD271, Jarid1B, and Nanog) were measured by Western blot in p21-siRNA transfected CD271 ${ }^{\text {high/ } /+}$ cells. G) The expression levels of stemness markers (CD133, CD271, Jarid1B, and Nanog) were measured by Western blot in miR-363-3p-inhibitor and pcDNA3.1-p21 (p21) co-transfected A2058 cells. ${ }^{*} p<0.05,{ }^{*} \mathrm{p}<0.05$. H and I) The proliferation of p21-siRNA transfected A2058 and WM793B cells were detected at the time points $24,48,72$ and $96 \mathrm{~h}$ by MTT assays. ${ }^{\star} \mathrm{p}<0.05 \mathrm{vs}$. Ctrl. All experiments were repeated three times. 
metastasis-associated lung adenocarcinoma transcript 1 which functions as a competing endogenous RNA in gallbladder cancer [42]. We speculate that HIF-2a might regulate miR-363-3p by inhibiting a lncRNA. The problem will be addressed in our future work.

In summary, our results illustrate that miR-363-3p is induced by HIF- $2 \alpha$ in melanoma cells and promotes their stemness via inhibiting p21. Our findings provide new thinking for understanding the mechanism of malignant transformation and a potential target for the treatment of melanoma.

\section{References}

[1] SVEDMAN FC, PILLAS D, TAYLOR A, KAUR M, LINDER $\mathrm{R}$ et al. Stage-specific survival and recurrence in patients with cutaneous malignant melanoma in Europe - a systematic review of the literature. Clin Epidemiol 2016; 8: 109-122. https://doi.org/10.2147/CLEP.S99021

[2] Vannini I, Fanini F, Fabbri M. Emerging roles of microRNAs in cancer. Curr Opin Genet Dev 2018; 48: 128-133. https:// doi.org/10.1016/j.gde.2018.01.001

[3] CHEN L, MA G, CAO X, AN X, LIU X. MicroRNA-331 inhibits proliferation and invasion of melanoma cells by targeting astrocyte-elevated gene-1. Oncol Res 2018. https://doi.or $\mathrm{g} / 10.3727 / 096504018 X 15186047251584$

[4] LONG J, LUO J, YIN X. MiR-338-5p promotes the growth and metastasis of malignant melanoma cells via targeting CD82. Biomed Pharmacother 2018; 102: 1195-1202. https:// doi.org/10.1016/j.biopha.2018.03.075

[5] FOMESHI MR, EBRAHIMI M, MOWLA SJ, KHOSRAVANI P, FIROUZI $J$ et al. Evaluation of the expressions pattern of miR-10b, 21, 200c, 373 and 520c to find the correlation between epithelial-to-mesenchymal transition and melanoma stem cell potential in isolated cancer stem cells. Cell Mol Biol Lett 2015; 20: 448-465. https://doi.org/10.1515/ cmble-2015-0025

[6] ZHANG PF, SHENG LL, WANG G, TIAN M, ZHU LY et al. miR-363 promotes proliferation and chemo-resistance of human gastric cancer via targeting of FBW7 ubiquitin ligase expression. Oncotarget 2016; 7: 35284-35292. https://doi. org/10.18632/oncotarget.9169

[7] DONG J, GENG J, TAN W. MiR-363-3p suppresses tumor growth and metastasis of colorectal cancer via targeting SphK2. Biomed Pharmacother 2018; 105: 922-931. https:// doi.org/10.1016/j.biopha.2018.06.052

[8] PARK H, LEE MJ, JEONG JY, CHOI MC, JUNG SG et al. Dysregulated microRNA expression in adenocarcinoma of the uterine cervix: clinical impact of miR-363-3p. Gynecol Oncol 2014; 135: 565-572. https://doi.org/10.1016/j.ygyno.2014.09.010

[9] LATCHANA N, REGAN K, HOWARD JH, ALDRINK JH, RANALLI MA et al. Global microRNA profiling for diagnostic appraisal of melanocytic Spitz tumors. J Surg Res 2016; 205: 350-358. https://doi.org/10.1016/j.jss.2016.06.085
[10] BELTRAN AS, ANGELA R, HAYDEE L, CHENG F, LIZARDI PM et al. Suppression of breast tumor growth and metastasis by an engineered transcription factor. PLoS One 2011; 6: e24595. https://doi.org/10.1371/journal. pone.0024595

[11] PHILIPPIDOU D, SCHMITT M, MOSER D, MARGUE C, NAZAROV PV et al. Signatures of microRNAs and selected microRNA target genes in human melanoma. Cancer Research 2010; 70: 4163-4173. https://doi.org/10.1158/00085472.CAN-09-4512

[12] REDMER T, WELTE Y, BEHRENS D, FICHTNER I, PRZYBILLA D et al. The nerve growth factor receptor CD271 is crucial to maintain tumorigenicity and stem-like properties of melanoma cells. PLoS One 2014; 9: e92596. https://doi. org/10.1371/journal.pone.0092596

[13] FANG D, NGUYEN TK, LEISHEAR K, FINKO R, KULP AN et al. A tumorigenic subpopulation with stem cell properties in melanomas. Cancer Res 2005; 65: 9328-9337. https://doi.org/10.1158/0008-5472.CAN-05-1343

[14] MONZANI E, FACCHETTI F, GALMOZZI E, CORSINI E, BENETTI A et al. Melanoma contains CD133 and ABCG2 positive cells with enhanced tumourigenic potential. Eur J Cancer 2007; 43: 935-946. https://doi.org/10.1016/j. ejca.2007.01.017

[15] BOIKO AD, RAZORENOVA OV, RIJN MVD, SWETTER SM, JOHNSON DL et al. Human melanoma-initiating cells express neural crest nerve growth factor receptor CD271. Nature 2010; 466: 133-137. https://doi.org/10.1038/nature09161

[16] FLOYD DH, ZHANG Y, DEY BK, KEFAS B, BREIT H et al. Novel anti-apoptotic microRNAs 582-5p and 363 promote human glioblastoma stem cell survival via direct inhibition of caspase 3, caspase 9, and Bim. PLoS One 2014; 9: e96239. https://doi.org/10.1371/journal.pone.0096239

[17] KARATAS OF, SUER I, YUCETURK B, YILMAZ M, OZ $B$ et al. Identification of microRNA profile specific to cancer stem-like cells directly isolated from human larynx cancer specimens. BMC Cancer 2016; 16: 853. https://doi. org/10.1186/s12885-016-2863-3

[18] ZBYTEK B, PEACOCK DL, SEAGROVES TN, SLOMINSKI A. Putative role of HIF transcriptional activity in melanocytes and melanoma biology. Dermatoendocrinol 2013; 5: 239-251. https://doi.org/10.4161/derm.22678

[19] WANG X, DONG J, JIA L, ZHAO T, LANG M et al. HIF2-dependent expression of stem cell factor promotes metastasis in hepatocellular carcinoma. Cancer Lett 2017; 393: 113-124. https://doi.org/10.1016/j.canlet.2017.01.032

[20] BHAGAT M, PALANICHAMY JK, RAMALINGAM P, MUDASSIR M, IRSHAD K et al. HIF- $2 \alpha$ mediates a marked increase in migration and stemness characteristics in a subset of Glioma cells under hypoxia by activating an Oct-4/ Sox-2- Mena (INV) axis. Int J Biochem Cell Biol 2016; 74: 60-71. https://doi.org/10.1016/j.biocel.2016.02.017

[21] XIE Y, LI W, FENG J, WU T, LI J. MicroRNA-363 and GATA1 are regulated by HIF-1 $\alpha$ in K562 cells under hypoxia. Mol Med Rep 2016; 14: 2503-2510. https://doi.org/10.3892/ mmr.2016.5578 
[22] SOHDA M, ISHIKAWA H, MASUDA N, KATO H, MIYAZAKI $\mathrm{T}$ et al. Pretreatment evaluation of combined HIF-1 1 , p53 and p21 expression is a useful and sensitive indicator of response to radiation and chemotherapy in esophageal cancer. Int J Cancer 2004; 110: 838-844. https:// doi.org/10.1002/ijc.20215

[23] REDMER T, WELTE Y, BEHRENS D, FICHTNER I, PRZYBILLA D et al. The nerve growth factor receptor CD271 is crucial to maintain tumorigenicity and stem-like properties of melanoma cells. PLoS One 2014; 9: e92596. https://doi. org/10.1371/journal.pone.0092596

[24] HUANG W, WAN C, LUO Q, HUANG Z, LUO Q. Genistein-inhibited cancer stem cell-like properties and reduced chemoresistance of gastric cancer. Int J Mol Sci 2014; 15: 3432-3443. https://doi.org/10.3390/ijms15033432

[25] YEH Y, HSIAO H, YEH Y, CHEN T, LI T. Inflammatory interferon activates HIF-1 $\alpha$-mediated epithelial-to-mesenchymal transition via PI3K/AKT/mTOR pathway. J Exp Clin Cancer Res 2018; 37: 70. https://doi.org/10.1186/s13046018-0730-6

[26] HOOD JL. Melanoma exosome induction of endothelial cell GM-CSF in pre-metastatic lymph nodes may result in different M1 and M2 macrophage mediated angiogenic processes. Med Hypotheses 2016: 94: 118-122. https://doi. org/10.1016/j.mehy.2016.07.009

[27] NI N, SONG H, WANG X, XU X, JIANG Y et al. Up-regulation of long noncoding RNA FALEC predicts poor prognosis and promotes melanoma cell proliferation through epigenetically silencing p21. Biomed Pharmacother 2017; 96: 1371-1379. https://doi.org/10.1016/j.biopha.2017.11.060

[28] PODUST VN, PODUST LM, GOUBIN F, DUCOMMUN B, HUBSCHER U. Mechanism of inhibition of proliferating cell nuclear antigen-dependent DNA synthesis by the cyclin-dependent kinase inhibitor p21. Biochemistry 1995; 34: 8869-8875.

[29] WANG X, QIAN R, ZHANG W, CHEN S, JIN H et al. MicroRNA-320 expression in myocardial microvascular endothelial cells and its relationship with insulin-like growth factor-1 in type 2 diabetic rats. Clin Exp Pharmacol Physiol 2009; 36: 181-188. https://doi.org/10.1111/j.14401681.2008.05057.x

[30] CONTI A, ROMEO SG, CAMA A, TORRE DL, BARRESI $\mathrm{V}$ et al. MiRNA expression profiling in human gliomas: upregulated miR-363 increases cell survival and proliferation. Tumour Biol 2016; 37: 14035-14048. https://doi. org/10.1007/s13277-016-5273-x

[31] MORIZANE R, FUJII S, MONKAWA T, HIRATSUKA $\mathrm{K}$, YAMAGUCHI $\mathrm{S}$ et al. miR-363 induces transdifferentiation of human kidney tubular cells to mesenchymal phenotype. Clin Exp Nephrol 2016; 20: 394-401. https://doi. org/10.1007/s10157-015-1167-2
[32] BELTRAN AS, RUSSO A, LARA H, FAN C, LIZARDI PM et al. Suppression of breast tumor growth and metastasis by an engineered transcription factor. PLoS One 2011; 6: e24595. https://doi.org/10.1371/journal.pone.0024595

[33] COVELLO KL, KEHLER J, YU H, GORDAN JD, ARSHAM AM et al. HIF-2 $\alpha$ regulates Oct-4: effects of hypoxia on stem cell function, embryonic development, and tumor growth. Genes Dev 2006; 20: 557-570. https://doi.org/10.1101/ gad.1399906

[34] OHNISHI S, MAEHARA O, NAKAGAWA K, KAMEYA $A$, OTAKI $\mathrm{K}$ et al. Hypoxia-inducible factors activate CD133 promoter through ETS family transcription factors. PLoS One 2013; 8: e66255. https://doi.org/10.1371/journal. pone.0066255

[35] PETRUZZELLI R, CHRISTENSEN DR, PARRY KL, SANCHEZELSNER T, HOUGHTON FD. HIF- 2 a regulates NANOG expression in human embryonic stem cells following hypoxia and reoxygenation through the interaction with an Oct-Sox cis regulatory element. PLoS One 2014; 9: e108309. https://doi.org/10.1371/journal.pone.0108309

[36] ABEL EV, APLIN AE. FOXD3 is a mutant B-RAF-regulated inhibitor of $\mathrm{G}(1)-S$ progression in melanoma cells. Cancer Res 2010; 70: 2891-2900. https://doi.org/10.1158/0008-5472. CAN-09-313

[37] HUMBERT L, GHOZLAN M, CANAFF L, TIAN J, LEBRUN J. The leukemia inhibitory factor (LIF) and p21 mediate the TGF $\beta$ tumor suppressive effects in human cutaneous melanoma. BMC Cancer 2015; 15: 200. https://doi. org/10.1186/s12885-015-1177-1

[38] YEW TL, CHIU FY, TSAI CC, CHEN HL, LEE WP et al. Knockdown of p21(Cip1/Waf1) enhances proliferation, the expression of stemness markers, and osteogenic potential in human mesenchymal stem cells. Aging Cell 2011; 10: 349361. https://doi.org/10.1111/j.1474-9726.2011.00676.x

[39] WU S, HUANG S, DING J, ZHAO Y, LIANG L et al. Multiple microRNAs modulate p21Cip1/Waf1 expression by directly targeting its 3' untranslated region. Oncogene 2010; 29: 2302-2308. https://doi.org/10.1038/onc.2010.34

[40] WU SQ, ZHANG LH, HUANG HB, LI YP, NIU WY et al. miR-299-5p promotes cell growth and regulates G1/S transition by targeting p21Cip1/Waf1 in acute promyelocytic leukemia. Oncol Lett 2016; 12: 741. https://doi.org/10.3892/ ol.2016.4621

[41] LI HT, ZHANG H, CHEN Y, LIU XF, QIAN J. MiR-423-3p enhances cell growth through inhibition of p21Cip1/Waf1 in colorectal cancer. Cell Physiol Biochem 2015; 37: 1044-1054. https://doi.org/10.1159/000430230

[42] WANG SH, ZHANG WJ, WU XC, WENG MZ, ZHANG $\mathrm{MD}$ et al. The lncRNA MALAT1 functions as a competing endogenous RNA to regulate MCL-1 expression by sponging miR-363-3p in gallbladder cancer. J Cell Mol Med 2016; 20: 2299-2308. https://doi.org/10.1111/jcmm.12920 